\title{
Assessment of Capacity Evaluation and Sedimentation of Totla Doh Reservoir,In Nagpur District By Remote sensing Technique.
}

\author{
${ }^{1}$ S.R.Mandwar, ${ }^{2}$ Dr. H.V. Hajare, ${ }^{3}$ Dr. A.R.Gajbhiye \\ ${ }^{1}$ Assistant Engineer Gr- 1, Water Resources Department, Nagpur. \\ ${ }^{2}$ Professor, Priyadarshani College of Engineering, Nagpur. \\ ${ }_{3}^{3}$ Professor, Yeshwantrao Chauhan College of Engineering, Nagpur.
}

\begin{abstract}
Water is essential for socio-economic development and for maintaining healthy economic component of growth, poverty reduction and equality. The livelihood of the poorest sector with higher rates of urbanization, increasing demand for drinking water will put stronger by 2030. The next 25 years are challenging to create hydropower stations, the higher food production at lower rate of water consumption, development of Industrial and Agriculture sector and the economical waste water treatments.

Water Resources Management aims at optimizing the available natural water flows and competing needs. Adding uncertainty, climate change will increase the complexity of managing water resources. The mounting challenges due to demand and supply of water, It becomes essential to utilize available storage in minimize rate.

It is well established fact that reservoirs constructed on rivers are subjected to sedimentation. A reservoir sedimentation is a natural phenomena. All the reservoirs are bound to suffer a loss in their storage potential because of silt load, over a period of time. To evaluate the performance of every Major and Medium dams, the accurate sedimentation analysis is essential in every 5-10 years of span. At present the most reliable method of assessment of sedimentation is Remote Sensing Technique.

Maharashtra Engineering Research Institute, ( MERI) Nashik, has conducted capacity assessment survey of several major and medium dams in Vidarbha Region by Satellite Remote Sensing (SRS) Technique. This Paper deals with the case study of Totla Doh dam for capacity evaluation and sedimentation.This also suggests necessity for planning the water use more effectively.
\end{abstract}

Key words : Sedimentation, Reservoir capacity, Satellite Remote Sensing ( SRS ), Mapping of water spread area, Area capacity curves, Cloud free satellite pass, and Evaluation of capacity of reservoir.

\section{Introduction:}

Remote sensing is an art and science of collecting information about earth's features without being in physical contact with it. Various features on earth surface reflect or emit electromagnetic energy depending upon their characteristics. The reflected radiation depends upon physical properties of the terrain and emitted radiation depends upon temperature and emissivity. The radiations are recorded by the sensors onboard satellite and then are transmitted back to earth. Discrimination between features depends on the fact that the response from different features like vegetation, soil, water is different and discernable. Data received at ground stations, is digitally or visually interpreted to generate thematic maps.

Remote sensing based reservoir capacity assessment surveys are essentially based on mapping of water-spread areas at the time of satellite over pass. It uses the fact that water-spread area of the reservoir reduces with the sedimentation at different levels. The water-spread area and the elevation information are used to calculate the volume of water stored between different levels. These capacity values are then compared with the originally calculated capacity values to find out change in capacity between different levels.

In the present study of estimating the sedimentation in Totla Doh Reservoir, IRS LISS III data with 24 meters resolution has been used .In this survey the live storage capacity between MDDL $464.00 \mathrm{~m}$. and FRL $490.00 \mathrm{~m}$. has been evaluated for sedimentation assessment. SRS survey of Totla Doh Reservoir have been conducted in 2002-03, 2006-07 and 2010-2011.

II. Salient Features Of Totla Doh Project :

The Totla Doh Reservoir is constructed in the year 1982-83 on the Pench river at Totla Doh village, in Ramtake Taluka of Nagpur district in Maharashtra .It is an Interstate Hydro cum Irrigation project of Maharashtra and Madhya Pradesh. The first impounding in the reservoir took place in year 1983-83. The salient features of the Totla Doh reservoir are as below. 


\begin{tabular}{|c|c|c|}
\hline 1 & Location & $\begin{array}{l}\text { Near village Totladoh, Taluk Ramtek, district } \\
\text { Nagpur, Maharashtra. } \\
\text { Latitude : } 21^{0}: 39^{\prime}: 30^{\prime \prime} \text { to } 21^{0}: 48^{\prime}: 35^{\prime \prime} \mathrm{N} \\
\text { Longitude : } 79^{0}: 07^{\prime}: 35^{\prime \prime} \text { to } 79^{0}: 17^{\prime}: 10^{\prime} \mathrm{E}\end{array}$ \\
\hline 2 & Year of first Impounding & $: 1982-83$. \\
\hline 4 & Important Reservoir Levels & $\begin{array}{l}\text { ( i ) Crest level of Spillway } \\
\text { ( ii ) MDDL } \\
\text { ( iii ) FRL } \\
\text { (iv) MWL } \\
\text { ( v ) TBL }\end{array}$ \\
\hline 5 & $\begin{array}{l}\text { Reservoir capacity data } \\
\text { (original ) }\end{array}$ & $\begin{array}{lc}\text { (i) Gross storage } & : 1241 \mathrm{Mm}^{3} \\
\text { ( ii ) Live storage } & : 1091 \mathrm{Mm}^{3} \quad \text { (iii } \\
\text { ) Dead storage } & : 150 \mathrm{~mm}^{3} \\
\end{array}$ \\
\hline 6 & Length of Dam & $\begin{array}{l}\text { (i) Earthen Dam } \\
\text { (ii ) Masonry Dam }\end{array}$ \\
\hline 7 & Maximum height of Dam & $: 74.50 \mathrm{~m}$ \\
\hline 8 & Total area of submergence & : $7771 \mathrm{Ha}$. \\
\hline 9 & Projects Benefits & Hydropower \&Irrigation \\
\hline
\end{tabular}

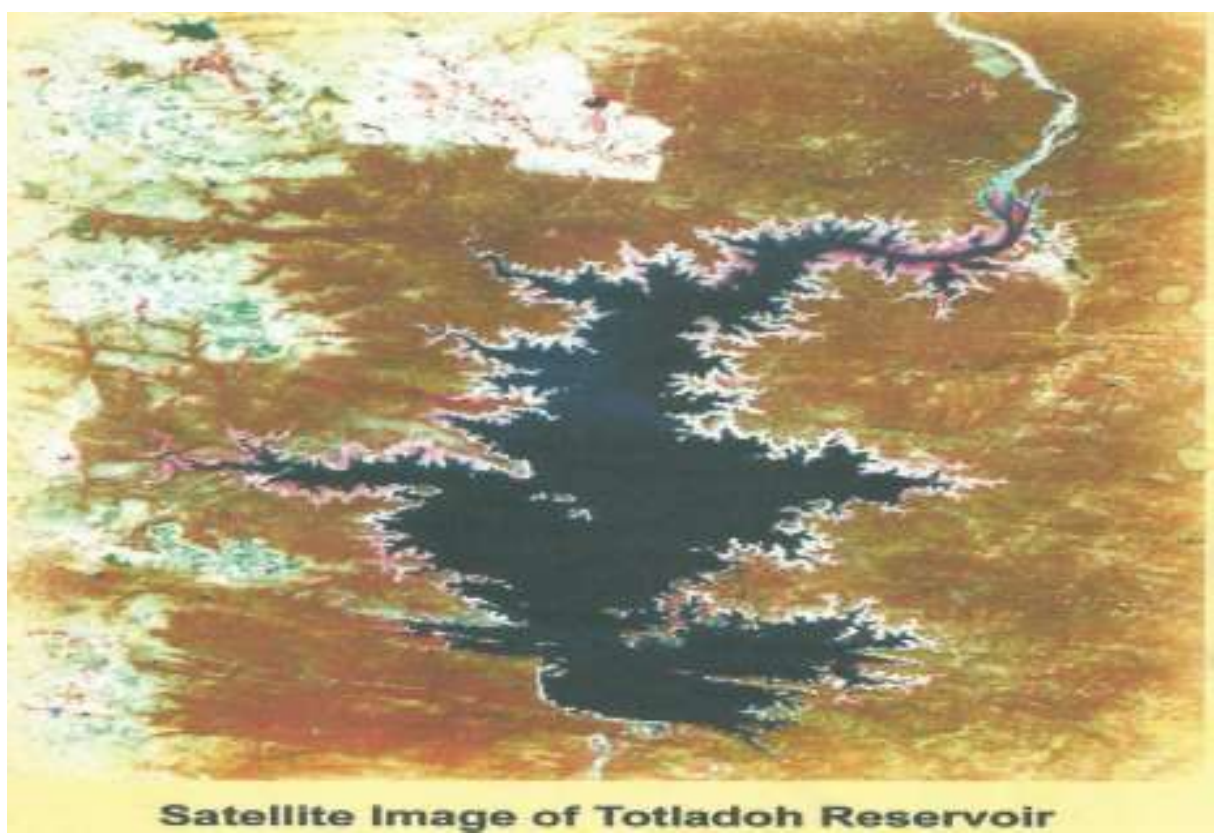

Figure No. 1

\section{Objectives Of The Study:}

The objectives of the study is to estimate the present storage capacity of Totla Doh Reservoir and capacity loss due to sedimentation, through Satellite Remote Sensing. Following objectives are achieved in the study.

- Updating of Elevation-Area-Capacity curves using satellite e data in live storage zone of Reservoir.

- Estimation of storage loss due to sedimentation in reservoir.

- To provide database for developing regional indices and rational sedimentation planning of future reservoirs.

\section{History Of Sedimentation Study:}

MERI. Nashik, had conducted sedimentation study of Totla Doh reservoir in 2002-03, 2006-07 and recently in 2010-11. In 2002-03, the study covered storage zone of reservoir between R.L. 463.00 m. to R.L. $488.18 \mathrm{~m}$. covering $90 \%$ of designed live storage zone and smaller portion of dead storage. In 2006-07 study covered 100\% live storage zone of reservoir between FRL $490.00 \mathrm{~m}$. and MDDL $464.00 \mathrm{~m}$. and some portion of dead storage. In the third study the reservoir zone between RL $458.30 \mathrm{~m}$. and RL $490.00 \mathrm{~m}$. has been covered. 
Critteria For Satellite Data Selection:

The selection of the satellite data for the study is based on the following.

1. To carry out the feasibility assessment of the given reservoir regarding availability of cloud free satellite data of dates of satellite pass corresponding to levels near MDDL as well as near FRL and at uniform interval to extent possible in between MDDL and FRL for the latest water year or maximum up to two previous water years.

2. To carry out sedimentation analysis through SRS technique to cover the entire live storage and available dead storage zones of the reservoir.

3. In case of inability to cover the entire live storage zone of reservoir due to non-availability of cloud free satellite data at FRL and MDDL, the study may be taken up if minimum of $80 \%$ of live storage capacity is covered by the available cloud free dates of satellite pass on maximum and minimum reservoir level.

\section{Methodology Of The Study:}

The basic concept is to find out the water spread area from satellite data for different water levels between MDDL and FRL. The difference between aerial spread of water between current year and earlier year is the aerial extent of silting at these levels. The methodology for estimation of live capacity of reservoir using remote sensing consist of following.

- Digital data base creation.

- Estimation of water-spread area.

- Calculation of reservoir capacity.

- Comparison with previous surveys.

- Estimation of live capacity loss due to sedimentation.

Findings Of Satellite Remote Sensing Study :

The satellite survey of Totla Doh reservoir has been conducted in 2002-03, 2006-07 and 2010-011. The findings of survey were compared with the original capacity table between MDDL and FRL. The findings of these three survey is tabulated as follows.

Table no. 1 Comparison of original capacity of Totla Doh reservoir with SRS survey.

\begin{tabular}{|c|c|c|c|c|c|c|c|c|c|}
\hline $\begin{array}{l}\text { Sr. } \\
\text { No. }\end{array}$ & Elevation & \multicolumn{2}{|c|}{$\begin{array}{c}\text { Original Year } \\
\mathbf{1 9 8 2 - 8 3} \\
\end{array}$} & \multicolumn{2}{|c|}{$\begin{array}{cc}\text { SRS } & \text { Year } \\
\mathbf{2 0 0 2 - 0 3} \\
\end{array}$} & \multicolumn{2}{|c|}{$\begin{array}{cc}\text { SRS } \quad \text { Year } \\
\mathbf{2 0 0 6 - 0 7} \\
\end{array}$} & \multicolumn{2}{|c|}{$\begin{array}{c}\text { SRS Year } \\
\mathbf{2 0 1 0 - 1 1} \\
\end{array}$} \\
\hline & in meters & $\begin{array}{l}\text { Area in } \\
\mathrm{Mm}^{2}\end{array}$ & $\begin{array}{l}\text { Capacity in } \\
\mathrm{Mm}^{3}\end{array}$ & $\begin{array}{l}\text { Area in } \\
\mathrm{Mm}^{2}\end{array}$ & $\begin{array}{l}\text { Capacity in } \\
\mathrm{Mm}^{3}\end{array}$ & $\begin{array}{l}\text { Area in } \\
\mathrm{Mm}^{2}\end{array}$ & $\begin{array}{l}\text { Capacity in } \\
\mathrm{Mm}^{3}\end{array}$ & $\begin{array}{l}\text { Area in } \\
\mathrm{Mm}^{2}\end{array}$ & $\begin{array}{l}\text { Capacity } \\
\mathrm{Mm}^{3}\end{array}$ \\
\hline 1 & 2 & 3 & 4 & 5 & 6 & 7 & 8 & 9 & 10 \\
\hline 1 & MDDL 464 & 15.048 & 0 & 11.633 & 0 & 11.597 & 0 & 11.498 & 0 \\
\hline 2 & 465 & 16.338 & 16.510 & 11.131 & 12.375 & 12.652 & 12.216 & 12.847 & 12.166 \\
\hline 3 & 466 & 17.727 & 32.819 & 14.708 & 26.289 & 14.226 & 25.745 & 14.277 & 25.722 \\
\hline 4 & 467 & 19.110 & 51.921 & 16.365 & 41.818 & 15.718 & 40.708 & 15.790 & 40.749 \\
\hline 5 & 468 & 20.508 & 71.004 & 18.106 & 59.046 & 17.326 & 57.221 & 17.388 & 57.332 \\
\hline 6 & 469 & 21.806 & 93.004 & 19.923 & 78.052 & 19.049 & 75.400 & 19.075 & 75.557 \\
\hline 7 & 470 & 23.283 & 114.995 & 21.826 & 98.919 & 20.884 & 95.357 & 20.852 & 95.514 \\
\hline 8 & 471 & 25.668 & 140.727 & 23.814 & 121.733 & 22.830 & 117.205 & 22.722 & 117.294 \\
\hline 9 & 472 & 28.042 & 166.460 & 25.888 & 146.577 & 24.884 & 141.054 & 24.687 & 140.991 \\
\hline 10 & 473 & 30.421 & 196.850 & 28.049 & 173.538 & 27.046 & 167.010 & 26.749 & 166.703 \\
\hline 11 & 474 & 32.799 & 227.241 & 30.298 & 202.704 & 29.313 & 195.182 & 28.912 & 194.526 \\
\hline 12 & 475 & 35.178 & 262.393 & 32.636 & 234.164 & 31.684 & 225.672 & 31.177 & 224.564 \\
\hline 13 & 476 & 37.556 & 297.544 & 35.065 & 268.007 & 34.157 & 258.585 & 33.547 & 256.918 \\
\hline 14 & 477 & 39.935 & 337.454 & 37.586 & 304.325 & 36.729 & 294.019 & 36.024 & 291.696 \\
\hline 15 & 478 & 42.313 & 377.363 & 40.200 & 343.211 & 39.400 & 332.076 & 38.610 & 329.006 \\
\hline 16 & 479 & 44.691 & 421.431 & 42.908 & 384.757 & 42.167 & 372.851 & 41.309 & 368.958 \\
\hline 17 & 480 & 47.070 & 466.698 & 45.711 & 429.059 & 45.028 & 416.441 & 44.122 & 411.666 \\
\hline 18 & 481 & 50.144 & 516.804 & 48.611 & 476.212 & 47.983 & 462.939 & 47.052 & 457.245 \\
\hline 19 & 482 & 53.218 & 566.910 & 51.609 & 526.315 & 51.028 & 512.436 & 50.101 & 505.813 \\
\hline 20 & 483 & 56.292 & 623.504 & 54.706 & 579.464 & 54.162 & 565.024 & 53.271 & 557.491 \\
\hline 21 & 484 & 59.366 & 680.099 & 57.903 & 635.761 & 57.384 & 620.789 & 56.566 & 612.402 \\
\hline 22 & 485 & 62.440 & 742.515 & 61.201 & 695.304 & 60.691 & 679.819 & 59.987 & 670.670 \\
\hline 23 & 486 & 65.514 & 806.102 & 64.602 & 758.198 & 64.082 & 742.198 & 63.537 & 732.423 \\
\hline 24 & 487 & 68.588 & 873.498 & 68.107 & 824.544 & 67.555 & 808.010 & 67.218 & 797.792 \\
\hline 25 & 488 & 71.662 & 942.063 & 71.717 & 894.448 & 71.108 & 877.334 & 71.032 & 666.908 \\
\hline 26 & 489 & 74.736 & 1016.797 & 75.433 & 968.014 & 74.739 & 950.251 & 74.983 & 939.907 \\
\hline 27 & FRL 490 & 77.710 & 1091.531 & 79.256 & 1045.350 & 78.447 & 1026.837 & 79.072 & 1016.925 \\
\hline
\end{tabular}


FIGURE 2

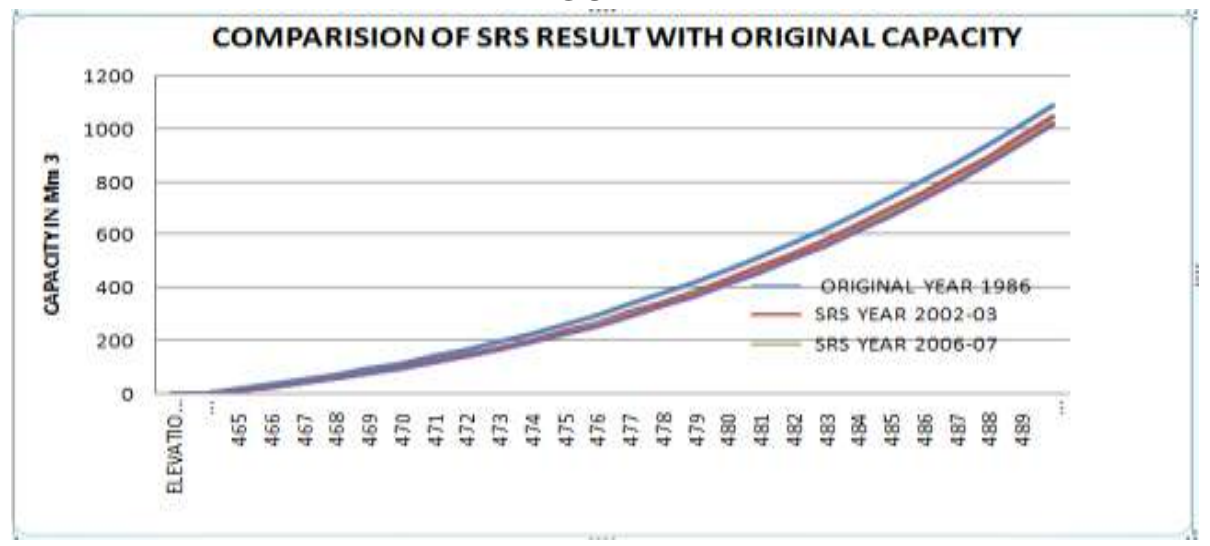

IV. Discussion And Conclusions:

The results of the SRS survey are expressed in Table 1 and Graph 1.From the findings of the results the rate of sedimentation between MDDL $464 \mathrm{~m}$. and FRL $490 \mathrm{~m}$. are as follows.

\begin{tabular}{|l|l|c|c|c|}
\hline $\begin{array}{l}\text { Sr. } \\
\text { no. }\end{array}$ & \multicolumn{1}{|c|}{ Details of the study } & $\begin{array}{l}\text { Reduction in } \\
\text { Live storage }\end{array}$ & $\begin{array}{c}\text { Period in } \\
\text { Years. }\end{array}$ & $\begin{array}{c}\text { Rate of } \\
\text { Sedimentation }\end{array}$ \\
\hline 1 & $\begin{array}{l}\text { Between original capacity1982-83 and SRS } \\
2002-03\end{array}$ & $46.181 \mathrm{Mm}^{3}$ & 20 & $2.31 \mathrm{Mm}^{3} / \mathrm{yr}$. \\
\hline 2 & $\begin{array}{l}\text { Between } 1^{\text {st }} \text { SRS 2002-03 and 2 } \\
07 .\end{array}$ & $18.514 \mathrm{Mm}^{3}$ & 4 & $4.63 \mathrm{Mm}^{3} / \mathrm{yr}$. \\
\hline 3 & $\begin{array}{l}\text { Between 2 } 2006- \\
07 .\end{array}$ & $9.912 \mathrm{Mm}^{3}$ & 4 & $2.48 \mathrm{Mm}^{3} / \mathrm{yr}$. \\
\hline 4 & $\begin{array}{l}\text { Between original capacity 1982-83 and 3 } \\
\text { SRS 2006-07. }\end{array}$ & $74.606 \mathrm{Mm}^{3}$ & 28 & $2.66 \mathrm{Mm}^{3} / \mathrm{yr}$. \\
\hline
\end{tabular}

The rate of sedimentation between 2002-03 and 2006-07 was $4.63 \mathrm{Mm}^{3} /$ yr. which was higher in comparison of other SRS reports. The average rate of sedimentation is $2.66 \mathrm{Mm}^{3} / \mathrm{yr}$. which is about $0.25 \%$ per year of original live storage $1091 \mathrm{Mm}^{3}$ of the Totla Doh reservoir. Thus the average rate of siltation is 6.23 Ha.m $/ 100 \mathrm{~km}^{2} /$ year. This rate of siltation is not alarming. The study of rate of siltation in the dead storage is essential. For this Hydrographic survey can be conducted after which the accurate rate of siltation of the reservoir can be predicted.

\section{Limitations Of The Satellite Remote Sensing:}

- The Remote Sensing based capacity estimation, works between FRL and the minimum water level in the reservoir only. Thus changes can be estimated only in this zone of reservoir. For the capacity estimation below minimum water level in reservoir, other method like hydrographic survey is to be conducted.

- Availability of cloud free dates throught reservoir operation period is the problem. Hence data from different year was selected .

- Remote Sensing technique gives accurate estimation for fan shaped reservoir where there is a considerable change in water-spread area for incremental change in water level,

- Another source of general error lies in the identification of tail end of reservoir particularly, in rainy season.

\section{References:}

[1] N. G . Kuralekar, (1984) Use of Remote Sensing Techniques in the hydrological studies in parts of Solapur of Maharashtra state. Proceedings of conference on development of ground water resources in Maharashtra. Bombay 222-225.

[2] U. C. Kothyari, Erosion and Sediment Yield : Global and Regional Perspectives ( proceedings of the Exeter Symposium, July 1996 ) IASH Publ. No. 236, 1996.

[3] Reservoir sedimentation Assessment Guide-line by Hydrological Studies and Information Department- SIH- Brasilia DF-2000

[4] A. K. Sinha, D. Dhar, ( 2005 ) Remote sensing and Geographic Information System ( GIS ) for Water Resources, Investigation, Development and Management,, All India Seminar on challenging problems in Water Resources Management and Development ,Nagpur 176-179.

[5] Y.V.N. Krishna Murthy, D.S. Pandit, ( 2005 ) Role of Remote Senssing in Water Resources Investigation, Development and Management. All , India Seminar on challenging problems in Water Resources Management and Development ,Nagpur 167-175.

[6] D. M. More, S. K. Kalvit, (2005). Assessment of Storage Capacity of Pench Project by Remote Sensing Technique. All India Seminar on challenging problems in Water Resources Management and Development ,Nagpur 180-184.

[7] Technical Report on Sedimentation Assessment and Storage Capacity Evaluation of Totla Doh Reservoir. Dist.- Nagpur through Satellite Remote Sensing by MERI- Nashik- 2007-08.

[8] Technical Report on Capacity Evaluation and Sedimentation Assessment in Totla Doh Reservoir, Dist.- Nagpur by SRS Technology. MERI-Nashik-2012-13. 